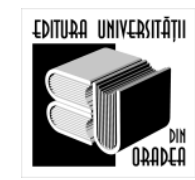

\title{
Assessing the anxiety level of a volleyball team
}

\author{
Ioan Sabin SOPA ${ }^{1 *}$ \\ 1. University "Lucian Blaga” Sibiu, Faculty of Science, Department of Environmental Science, Physics, Physical \\ Education and Sport, Address: Str. Dr. Ion Raţiu, No. 5-7, Sibiu, Romania, e-mail: sabin.sopa@ulbsibiu.ro \\ * Corresponding author
}

Citation: Sopa, I.S. (2021). Assessing the anxiety level of a volleyball team. Geosport for Society, 14(1), 47-55. https://doi.org/10.30892/gss.1405-071

Article history: 21.04.2021; Revised: 25.05.2021; Accepted: 24.06.2021, Available online: 30.06.2021

\begin{abstract}
Modern sport activity implies a lot of stress and anxiety, factors that can limit the performance level of a sportive in any category. The study focused on highlighting the importance of assessing the level of anxiety of a volleyball team. The research took place in the season 2019-2020, between 01 September 2019 and 31 March 2020, at the women volleyball club ACS Alpha Sport Team from Sibiu, Romania. The research sample was the mini volleyball representative of ACS Alpha Sport Team, composed of 15 volleyball players of female gender $(n=15)$, with age between 8-11 years old $(10.07 \pm 2.04$ years old) experience of $1-2$ years. The research method used was the Sport Competition Anxiety Test (SCAT) used to assess the anxiety level of the sportive before and after the competition, also, the questionnaire results were analyzed using descriptive statistic indicators. The research of our investigation showed that the initial anxiety level evaluated at the initial testing in September 2019 (average 23.33) was considered high, the final evaluation of anxiety showed real improvement in the anxiety level (average of 17.33). The research conclusions highlighted the idea that using special training for psychological preparation, playing official games, and friendly games can improve mental strength and reduce anxiety.
\end{abstract}

Keywords: anxiety, competition stress, volleyball

\section{Introduction}

Sports psychology is a branch of psychology that applies psychological concepts to sports or exercise. These values are often used to improve efficiency. The sport psychologist is interested in helping every sport participant reach his or her potential as an athlete. If helping a young athlete develops self-control and confidence results in superior athletic performance (Ramakrishnan et al., 2015).

Anxiety has become a fundamental topic in sport psychology and has undergone extensive research due to its impact on performance. Anxiety plays an 
essential role in the acquisition of motor skills as well as athletic performance. Anxiety can either increase or decrease performance (Kar, 2013). An emotion that is characterized by feelings of dread and tension. It is not emotionally neutral, unlike arousal, which is at the negative end of the affect spectrum (Cox, 2002).

Athletes, whether novice or elite, whether young or old, often feel anxiety. In this scenario, even though an athlete has worked diligently, practiced, and planned a mature technique, the athlete will not perform optimally (Hasanah and Refanthira, 2019). In this situation, an emphasis on physical fitness and the correct technique would not be enough to motivate an athlete to succeed optimally. Coaches and athletes must be mindful that psychological factors may have a significant impact on athlete success. Psychology is regarded as one of the most important aspects in achieving peak success and well-being in athletics (Dosil, 2006).

Anxiety is a natural reaction to challenges in the world, and it serves as part of the planning for the "fight or flight" response. Sporting rivalry promotes related psychological and physiological reactions because the ego, or our sense of selfesteem, is often threatened (Dandona, 2015). Essentially, this occurs when the demands of preparation or competition outweigh one's perceived skill, anxiety is the inevitable outcome. Anxiety is one of the most exciting and essential areas of focus in sport psychology and has continued to attract tremendous research interest (Weiss and Gill, 2005).

Several authors have regarded competitive anxiety as one of the most studied areas in the discipline of sport psychology (Mellalieu et al., 2006; Wadey and Hanton, 2008). It has been defined as "a trait and/or state-like response to a stressful sport-related situation, which the individual perceives as potentially stressful, resulting in a range of cognitive appraisals, behavioral responses, and physiological arousals" (Ford et al., 2017; Ong and Chua, 2021).

Generally, there are two types of anxiety: state anxiety and trait anxiety (Kar, 2013). State anxiety involved feeling of apprehension, tension, fear, and increased physiological arousal (Kar, 2013). This is an immediate emotional state response to the specific situation. State anxiety also consists of somatic and cognitive anxiety (Kar, 2013). Somatic anxiety is closely related to physiological aspects of anxiety, including physical symptoms such as rapid heartbeat, shortness of breath and muscular (Martinent et al., 2010). Another component of state anxiety is cognitive anxiety which refers to worry and emotional distress for upcoming events (Filaire et al., 2001). Trait anxiety involves an experience of anxiety over a long period towards stressful environments (Kornspan, 2012). At any point of life, everybody has the risk of experiencing psychological disorders such as fatigue, depression, and anxiety (Khabiri, 2018). Anxiety is often experienced by athletes, amateur and elite sports athletes, either young or mature athletes (Hasanah and Refanthira, 2020). Athletes experience anxious thoughts just before the crucial games and tournaments due to self, coaches and team management (Khan et al., 2011). These reflexions may have an effect on on-field performance either positively or negatively depending on the attitude of athletes and their background. Nayek and Chatterjee, (2013), mental skill (Sangari et al., 2013), the strength of opponent team (Abenza et al., 2009), strength of own team (Kar, 2013; Szabo et al., 2014) etc. 


\section{Methods of research}

The primary method of research was the SCAT (Sport Competition Anxiety Test) that was used for assessing the anxiety level of the sportive before and after the competition. The results of the questionnaire were analyzed using descriptive statistic indicators.

The Sport Competition Anxiety Test (SCAT) developed by Rainer Martens in 1977 and actualized by the same author in 1990 (Martens et al., 1990) was used to measure sports-related competition anxiety. Before conducting the test, the procedure of the questionnaire and the purpose of the test were briefly clarified to all subjects for better comprehension and motivation. The SCAT questionnaire contains fifteen questions, and the subjects were asked to respond franckly to each question about how they felt in general at the time of competition with one of the following variants of answer: Rarely, Sometimes, Often. Scores obtained for each question were calculated and added, representing an individual's total score on Sports Competition Anxiety (SCAT Score).

The questionnaire had 15 items with three variants of an answer, each response had a preset number of points attributed, and in the end, all the points were summed, and the result was interpreted.

Analyze of the questionnaire: each question received a certain number of points, depending on the level of anxiety they were analyzing. Each athlete's answer was marked with $0,1,2$, or 3 points, after which all the points were added, and they were classified in a level of anxiety (small, medium, or high). Questions 1, 4, 7, 10, and 13 received 0 points regardless of the athletes' answers.

The interpretation scale showed that subjects with a lower score than 17 points had a low anxiety level, subjects that scored between 17 points and 24 points have an average level of anxiety and subjects with more than 24 points had a high level of anxiety. Descriptive Statistic (Mean, Standard Deviation), Independent t-test was applied to analyze and compare the degree of Sports Competitive Anxiety of ACS Alpha Sport Team volleyball players. The level of significance of $p$ was set at 0.05 .

\section{Study Design and Subjects}

The research took place in the season 2019-2020, between 01 September 2019 and 31 March 2020, at the women volleyball club ACS Alpha Sport Team from Sibiu, Romania. The sample of research was the mini volleyball representative of ACS Alpha Sport Team, composed by 15 volleyball players of female gender $(n=15)$, with age between 8-11 years old (10.07 \pm 2.04 years old) with an experience of 1-2 years. The study took place at the University "Lucian Blaga" from Sibiu having the approval of the Ethic Committee and respecting the Declaration of Helsinki (2013). It also met the ethical standards for Sport and Exercise Science Research. Since the General data protection regulation entered into the appliance on 25 May 2018 (Regulation (EU) 2016/679).

The research protocol and the purpose of the experiment were explained to all participants in advance, and because it was a study that involved minors, and at the beginning of the experiment, the written informed consent was obtained from the parents. 
The research was divided in two parts; the initial testing that took place at the beginning of the season 2019-2020 in September 2019, and the second part of the research the final evaluation of the anxiety at the end of the season in February 2020.

\section{Results}

The research results part of the article was structured in two parts, the Initial test results with Table 1 and Figure 1 and the second part that analyzed the results from the Final test with Table 2 and Figure 2. Also, the results from the initial to the final testing were compared and can be seen in Figure 3.

Table 1. Initial test for competition anxiety of the team

\begin{tabular}{|c|c|}
\hline Subjects & Sport competition anxiety index \\
\hline Subject 1 & 25 \\
\hline Subject 2 & 24 \\
\hline Subject 3 & 25 \\
\hline Subject 4 & 24 \\
\hline Subject 5 & 23 \\
\hline Subject 6 & 26 \\
\hline Subject 7 & 20 \\
\hline Subject 8 & 23 \\
\hline Subject 9 & 22 \\
\hline Subject 10 & 24 \\
\hline Subject 11 & 20 \\
\hline Subject 12 & 25 \\
\hline Subject 13 & 25 \\
\hline Subject 14 & 23 \\
\hline Subject 15 & 21 \\
\hline Average & $\mathbf{2 3 . 3 3}$ \\
\hline Standard deviation & $\mathbf{1 . 8 8}$ \\
\hline Min & $\mathbf{2 0}$ \\
\hline Max & $\mathbf{2 6}$ \\
\hline Median & $\mathbf{2 4}$ \\
\hline Module & $\mathbf{2 5}$ \\
\hline
\end{tabular}

Table 1 presents the initial testing results at the anxiety test, showing an average 23.33 anxiety value considered using the anxiety level scale as an average level of anxiety, with the highest value of 26 and a low value of 20 . As a first conclusion of the initial anxiety assessment, we can say that the level of sport competition anxiety in the volleyball team was raised; our players have a terrible anxiety tolerance due to inexperience and fear of losing.

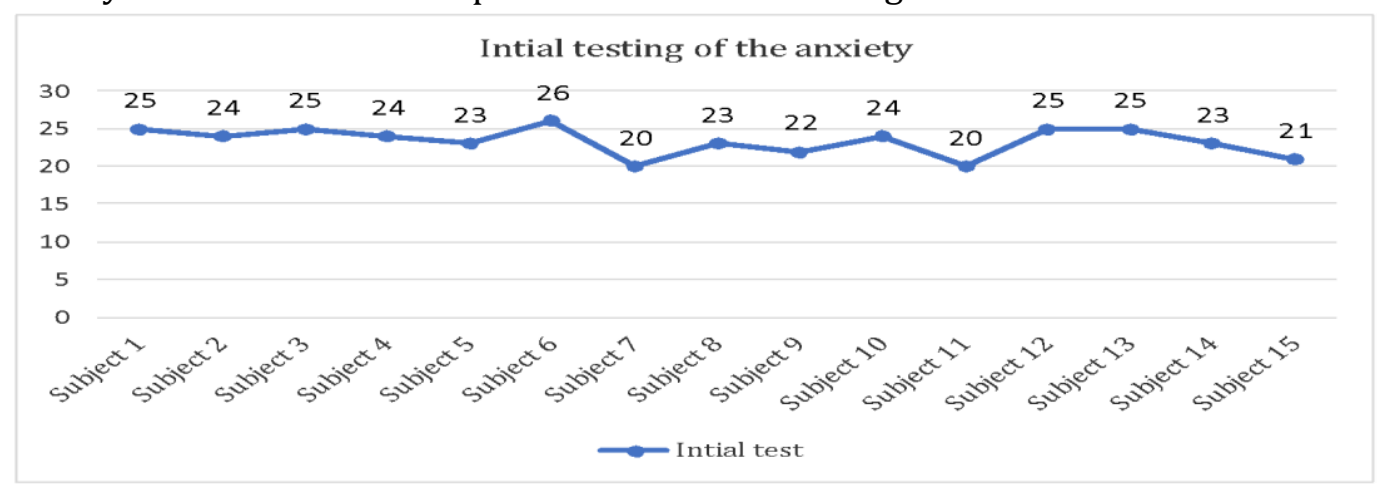

Figure 1. The initial testing of the anxiety 
The second part of the research included the final evaluation of the anxiety level of the volleyball team. After six months of games and mental preparation, the anxiety test was repeated, and the final evaluation results were registered (Table 2 and Figure 2) and compared with the initial assessment.

Table 2. Initial test for competition anxiety of the team

\begin{tabular}{|l|c|}
\hline \multicolumn{1}{|c|}{ Subjects } & Sport competition anxiety index \\
\hline Subject 1 & 20 \\
\hline Subject 2 & 17 \\
\hline Subject 3 & 19 \\
\hline Subject 4 & 16 \\
\hline Subject 5 & 15 \\
\hline Subject 6 & 21 \\
\hline Subject 7 & 11 \\
\hline Subject 8 & 15 \\
\hline Subject 9 & 19 \\
\hline Subject 10 & 20 \\
\hline Subject 11 & 14 \\
\hline Subject 12 & 16 \\
\hline Subject 13 & 22 \\
\hline Subject 14 & 21 \\
\hline Subject 15 & 14 \\
\hline Average & $\mathbf{1 7 . 3 3}$ \\
\hline Standard deviation & 3.22 \\
\hline Min & 17 \\
\hline Max & 22 \\
\hline Median & 17 \\
\hline Module & 20 \\
\hline
\end{tabular}

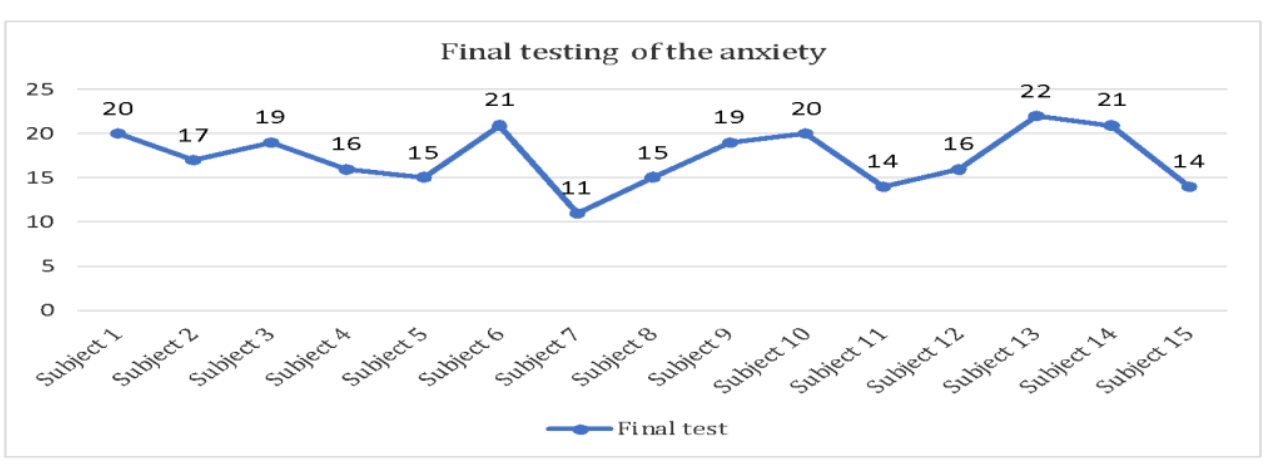

Figure 2. The final testing of the anxiety level

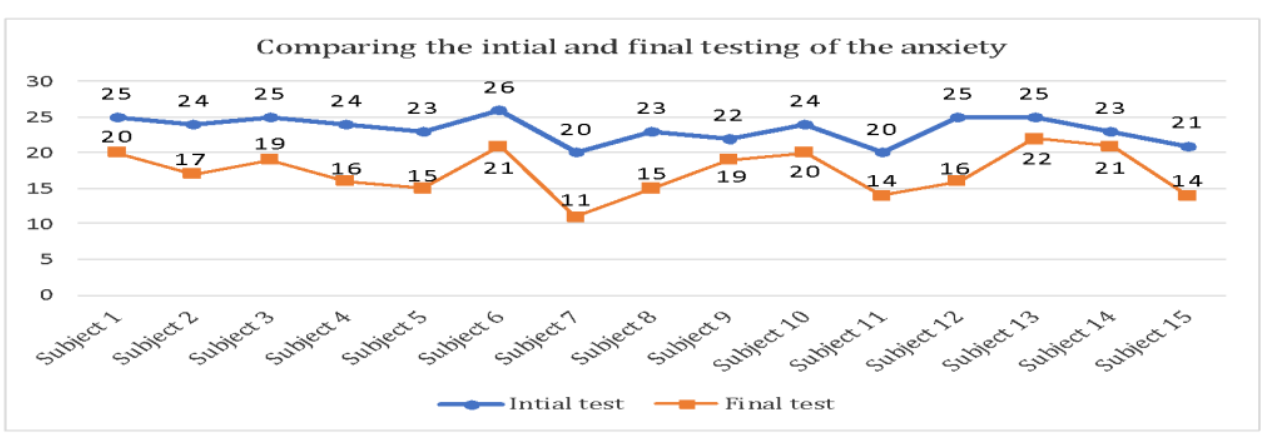

Figure 3. Comparing the results of the initial and final testing of the anxiety level 


\section{Discussion}

There has been lesser research conducted in trait anxiety, which has been described as a predisposition to evaluate situations as threatening, thus resulting in state anxiety (Mellalieu et al., 2006). The research results showed that anxiety levels influence sportive performance also depending on their experience level and skills. The research of our investigation showed that the initial anxiety level evaluated at the initial testing in September 2019 (average 23.33) was considered high, highlighting the idea that players from our team were scared about starting the competition. After six months of training, psychological evaluation and competition, the final evaluation of anxiety showed real improvement in the anxiety level (average of 17.33) highlighting the idea that using special training for psychological preparation, playing official games and also friendly games can improve the mental strength and also reduce the anxiety level.

Research in competitive anxiety has emerged once again in the past few years, with the efforts of researchers such as Jones, Mullen, and Hardy (2019) and Cheng and Hardy (2016) at the forefront of advancing the conceptualization and understanding of the area. These researchers propose a modified multidimensional framework of competitive anxiety, which is represented by three dimensions: Cognitive anxiety, which has the subcomponents of worry and self-focused attention (both private and public); physiological anxiety, which has the subcomponents of autonomic hyperactivity and somatic tension; and a regulatory dimension, which reflects the adaptive nature of the anxiety response, and consists of the subcomponent perceived control (Cheng and Hardy, 2016; Cheng et al., 2009; Jones et al., 2019, Ong and Chua, 2021).

Our findings are supported by the other research study by Qureshi, 2015, indicating a significant difference between the means of Table Tennis players and Volleyball players on scores of sports competition anxiety test score. The findings of our study are also in line with the findings by Rastogi and Katiyar, 2014. They discovered a major disparity in the scores of sport performance anxiety measures between chess players and cricket players. Another research, Kerketta (2015), found no substantial difference between the Competitive Anxiety of the two groups of District level Volleyball and Soccer players of Bilaspur. A study by Khan and Aziz, 2015, revealed the same contradictory result with our study as they found no significant difference between basketball players and track running athletes of their sports competition anxiety.

Carter and Weissbrod (2011) explored the relationship between gender and enjoyment of competition and various indicators of mental health and adjustment in a sample of college students who report that they highly value athletics. The Sport Anxiety Scale, Multi-perfectionism Scale, State-Trait Anxiety Inventory (Trait), Beck Depression Inventory, and Perception of Competition Scale were completed by 137 students. According to the findings, among women, satisfaction of competition was correlated with lower levels of athletic anxiety, as well as a strong association between positive self-perception when winning and self-and socially oriented perfectionism, as well as the relationship between poor perception when failing and self-and socially oriented 
perfectionism. In males, satisfaction of competition was associated with lower levels of general anxiety and depression, but not athletic anxiety.

Several papers explored the planning component of psychology in training (Szabo et al., 2020, Sopa and Szabo, 2015), planning the growth of strength (Tulbure et al., 2020), and the importance of psychology in the game of volleyball (Szabo, 2014; Szabo, 2015a; Szabo, 2015b; Szabo and Sopa, 2015; Szabo et al., 2019). I came across an article that addressed also the planning aspect of stress management among students (Popa et al., 2020) as well as one that addressed the sports psychopedagogical planning aspect (Ardelean et al., 2020; Ardelean et al., 2021).

Past research has demonstrated the impact that competitive anxiety can have on sporting performance, with a meta-analysis by Woodman and Hardy (2003) indicating a significant adverse effect for cognitive anxiety on sport performance. Other studies have shown that high anxiety situations cause athletes to engage in excessive error monitoring (Masaki et al., 2017); reduce anticipation timing performance (Duncan et al., 2016); decrease search rate and processing efficiency (Nieuwenhuys et al., 2008); and have a negative effect on shooting accuracy in soccer (Wilson et al., 2009). Competitive anxiety has also been shown in past research to heighten the risk of sport injury (Ford et al., 2017), with a review study indicating that competitive trait anxiety is a risk factor for musculoskeletal injury in athletes (Cagle et al., 2017; Ong and Chua, 2021).

\section{Conclusions}

The anxiety level represents a big issue in nowadays sport performance having a significant impact on the evolution of sport teams. Anxiety manifests many times before essential competitions or official games, highlighting the lack of mental preparation or a low level of experience. This mental blocking can affect the team's performance and diminish the level of anxiety has proven to also improve the results of sports teams. The study focused on analyzing the anxiety level of a volleyball team. It was structured on two evaluations, one in September 2019 - the initial evaluation of anxiety level, and one in February 2020 that analyzed the final level of anxiety of the team. It was observed that the final anxiety level (average 17.33) was lower than the initial one (23.33). The conclusions of our investigation highlighted that anxiety represents a serious problem in sport competition and that if we train our team with mental coaching and psychological evaluation, we can prevent the rise of the anxiety level and also improve sportive results.

\section{References}

Ardelean M., Neagu N., Szabo, D. A., (2021). Pedagogical considerations regarding the structure of high school upper cycle syllabuses, for the "Theoretical Sports Training" school subject (Note II). Health, Sports \& Rehabilitation Medicine, 22(1), 36-39. https://doi.org/10.26659/pm3.2021.22.1.36

Ardelean M., Neagu N., Szabo, D. A., (2020). Pedagogical considerations regarding the structure of high school lower cycle syllabuses, for the "Theoretical Sports Training" school subject (Note I). Health, Sports \& Rehabilitation Medicine, 21(4), 256-259. https://doi.org/10.26659/pm3.2020.21.4.256

Abenza, L., Alarcon, F., Pinar, M.I., Urena, N. (2009). Relationship between the anxiety and performance of a basketball team during competition. Revista de Psicologia Deporte, 18, 409-413. 
Cagle, J.A., Overcash, K.B., Rowe, D.P., \& Needle, A.R. (2017). Trait anxiety as a risk factor for musculoskeletal injury in athletes: A critically appraised topic. International Journal of Athletic Therapy and Training, 22(3), 26-31. https://doi.org/10.1123/ijatt.2016-0065

Carter, M.M., Weissbrod, C.S. (2011). Gender differences in the relationship between competitiveness and adjustment among athletically identified college students. Scientific Research, 2(2), 85-90.

Cheng, W.-N. K., Hardy, L., \& Markland, D. (2009). Toward a three-dimensional conceptualization of performance anxiety: Rationale and initial measurement development. Psychology of Sport and Exercise, 10(2), 271-278. https://doi.org/10.1016/j.psychsport.2008.08.001

Cheng, W.-N. K., \& Hardy, L. (2016). Three-dimensional model of performance anxiety: Tests of the adaptive potential of the regulatory dimension of anxiety. Psychology of Sport and Exercise, 22, 255-263.

Cox, R. H. (2002). Sport psychology: Concepts and applications (5th Ed.). New York: McGraw Hill.

Dandona, A. (2015). A Study on Anxiety of Sports and Non-sports Personnel. International Journal of Health, Physical Education and Computer Science in Sports, 18(1), 7-12.

Dosil, J. (2006). The Sport Psychologist's Handbook: A Guide for Sport-Specific Performance Enhancemnet. John Wiley \& Sons Ltd. DOI:10.1002/9780470713174

Duncan, M.J., Smith, M., Bryant, E., Eyre, E., Cook, K., Hankey, J., Jones, M.V. (2016). Effects of increasing and decreasing physiological arousal on anticipation timing performance during competition and practice. European Journal of Sport Science, 16(1), 27-35. https://doi.org/10.1080/17461391.2014.979248

Filaire, E., Sagnol, M., Ferrand, C., Maso, F., \& Lac, G. (2001). Psychophysiological stress in judo athletes during competitions. Journal of Sports Medicine and Physical Fitness, 41(2), 263-268.

Ford, J.L., Ildefonso, K., Jones, M.L., \& Arvinen-Barrow, M. (2017). Sport-related anxiety: Current insights. Open Access Journal of Sports Medicine, 8, 205-212.

Hasanah, U., Refanthira, N. (2019). Human problems: competitive anxiety in sport performer and various treatments to reduce it, Advances in Social Science, Education and Humanities Research, 395, 144-148.

Hasanah, U., Refanthira, N. (2020). Human Problems: Competitive Anxiety in Sport Performer and Various Treatments to Reduce It. Advances in Social Science, Education and Humanities Research, Conference: Proceedings of the $5^{\text {th }}$ ASEAN Conference on Psychology, Councelling, and Humanities (ACPCH 2019), 395, 144-147. https://doi.org/10.2991/assehr.k.200120.031

Jones, E.S., Mullen, R., \& Hardy, L. (2019). Measurement and validation of a three factor hierarchical model of competitive anxiety. Psychology of Sport and Exercise, 43, 34-44. https://doi.org/10.1016/j.psychsport.2018.12.011

Kar, S. (2013). Measurement of Competition Level Anxiety of College Level Athletes by Using SCAT. International Journal of Engineering Science and Innovative Technology, 2(3), 367-75.

Kerketta, I. (2015). A Comparative study of sports competition Anxiety between district evels male Volleyball and soccer players. International Journal of Physical Education, Sports and Health. 1(3), 53-55.

Khabiri, M., Ali Moghadam Zadeh, Kalash, R.M., Asadi, A., Mehrsafar, A.H. (2018). The effect of positive self-talk intervention on psychophysiological responses of competitive anxiety and self-confidence in elite athletes. Neuropsychology, 3(4), 93-102.

Khan, Z., Haider, Z., Ahmad, N., \& Khan, S. (2011). Sports Achievement. Motivation and Sports Competition Anxiety: A Relationship Study. Journal of Education and Practice, 2(4), 1-5.

Kornspan, A. S. (2012). History of Sport and Performance. The Oxford Handbook of Sport and Performance Psychology, 3.

Martens, R. (1977). Sports competitive Anxiety Test. Champaign III: Human kinetics.

Martens, R., Burten, D., Vealey, R., Bump, L. Smith, D. (1990). The Development of the Competitive State Anxiety Inventory (CSA-2). Champaign, Illinois.

Martinent, G., Ferrand, C., Guillet, E., Gautheur, S. (2010). Validation of the French version of the Competitive State Anxiety Inventory-2 Revised (CSAI-2R) including frequency and direction scales. Psychology of Sport and Exercise, 11(1), 51-57. doi:10.1016/j.psychsport.2009.05.001

Masaki, H., Maruo, Y., Meyer, A., \& Hajcak, G. (2017). Neural correlates of choking under pressure: Athletes high in sports anxiety monitor errors more when performance is being evaluated. Developmental Neuropsychology, 42(2), 104-112.

Mellalieu, S. D., Hanton, S., \& Fletcher, D. (2006). A competitive anxiety review: Recent directions in sport psychology research. In S. Hanton \& S. D. Mellalieu (Eds.), Literature reviews in sport psychology(pp. 1-45). Hauppauge, NY: Nova Science. 
Nayek, B., Chatterjee, K. (2013). Comparative study on pre-competition anxiety between national and state level women athletes. IOSR Journal of Sports and Physical Education, 1(2), 33-6.

Nieuwenhuys, A., Pijpers, J. R., Oudejans, R. R., \& Bakker, F. C. (2008). The influence of anxiety on visual attention in climbing. Journal of Sport and Exercuse Psychology, 30(2), 171-185. https://doi.org/10.1123/jsep.30.2.171

Ong, N. C. H., \& Chua, J. H. E. (2021). Effects of psychological interventions on competitive anxiety in sport: A meta-analysis. Psychology of Sport and Exercise, 52(2021) 101836 https://doi.org/10.1016/j.psychsport.2020.101836

Qureshi, D. R. (2015). Comparative Study of Anxiety Test between College Level Table Tennis and Volleyball Players. Scholars Impact, 2(1), 41-44.

Popa C. O., Schenk A., Rus A., Szasz S., Suciu N., Szabo D.A., Cojocaru C. (2020). The Role of Acceptance and Planning in Stress Management for Medical Students, Acta Marisiensis - Seria Medica, 66(3), 101-105.

Ramakrishnan, K. S., Sathya, P., Bhavi, G. (2015). Assessment of Anxiety in Sports Person Pre \& Post Sports PerfomanceA Study on: Levels ofAnxiety inIndividual Vs Group Sport. International Journal of Innovative Research in Science, Engineering and Technology, 4(9), 8901-8905. https://doi.org/10.15680/IJIRSET.2015.0409085

Sangari, M., Fotrousi, F., Masrour, F. F. (2012). Relationship between mental skill and competitive anxiety in female national football players. World Appl. Sci. J., 20(8), 1175-8.

Sopa, I.S., Szabo, D.A. (2015). Testing agility and balance in volleyball game. Discobolul Phys Educ Sport Kinetother J, 11(41), 167-174.

Szabo, D.A. (2015a). Modalities of Using the Information Provided by the Statistical Program Click and Scout for Improving the Outside Hitters Service Efficiency in Volleyball Game. The European Proceedings of Social \& Behavioral Sciences EpSBS, XI, 341-347. http://dx.doi.org/10.15405/epsbs.2016.06.47

Szabo, D.A. (2015b). Study on improving the service unforced errors in volleyball game by using a statistical software. Conference proceedings of eLearning and Software for Education (eLSE), 3, 320-326.

Szabo, D.A., \& Magdaș, L. (2014). Increasing the defensive efficiency in volleyball using the statistical program "Click\&Scout". Conference proceedings of eLearning and Software for Education (eLSE), 1, 223-228.

Szabo, D.A., Neagu, N., \& Sopa, I.S. (2020). Research regarding the development and evaluation of agility (balance, coordination and speed) in children aged 9-10 years. Health, Sports \& Rehabilitation Medicine, 21(1), 33-40. https://doi.org/10.26659/pm3.2020.21.1.33

Szabo, D.A., Neagu, N., Teodorescu, S., \& Sopa, I.S. (2019). Modalities of exploatation the information provided by the Click \& Scout statistical program in preparing volleyball attack players. International Journal of Applied Exercise Physiology, 8(2.1), 852-859.

Szabo, DA., \& Sopa, I.S. (2015). Study on the Interpretation of the Results in a Volleyball Game by Using a Specific Program of Statistics. Procedia Social and Behavioral Sciences, Elsevier Publication, 180C, 1357-1363.

Szabo, A., Szucs, A., Gaspar, Z., Sule, K. (2014). Anxiety and affect in successful and less successful elite female basketball players: In-situ sampling before six consecutive games. Lase Journal of Sports Science, 5(2), 75-92.

Tulbure R. E., Neagu N., Szabo, D. A., (2020). Comparative study on the development of the motor skill (strength) through the circuit method versus dynamic games in physical education classes. Health, Sports \& Rehabilitation Medicine, 21(4), 223-230. https://doi.org/10.26659/pm3.2020.21.4.223

Wadey, R., \& Hanton, S. (2008). Basic psychological skills usage and competitive anxiety responses: perceived underlying mechanisms. Research Quarterly for Exercise and Sport, 79(3), 363-373. https://doi.org/10.1080/02701367.2008.10599500

Weiss, M. R., Gill, D. L. (2005). What goes aroung: re-emerging themes in sport and exercise psychology. Research Quarterly for Exercise and Sport, 76, 71-87.

Wilson, M. R., Wood, G., \& Vine, S. J. (2009). Anxiety, attentional control, and performance impairment in penalty kicks. Journal of Sport and Exercise Psychology, 31(6), 761-775.

Woodman, T., \& Hardy, L. (2003). The relative impact of cognitive anxiety and self-confidence upon sport performance: A meta-analysis. Journal of Sports Sciences, 21(6), 443-457. 